Artigo Original

\title{
Avaliação das atividades antifúngica, antimicobacteriana e larvicida de Duroia macrophylla e D. saccifera
}

\section{Evaluation of antifungal, antimycobacterial and larvicide activity of the Duroia macrophylla and D. saccifera}

Ana Júlia Reis ${ }^{1}$, Lillian Lucas Carrion ${ }^{1}$, Katiane Rodrigues ${ }^{1}$, Juliana Montelli Fenalti ${ }^{1}$, Tais Mata-Santos ${ }^{1}$, Carlos James Scaini ${ }^{1}$, Daiane Martins ${ }^{2}$, Denny William de Oliveira Mesquita $^{2}$, Adriana Spirotto Stein Mesquita ${ }^{2}$, Cecília Verônica Nunez ${ }^{2}$, Pedro Eduardo Almeida da Silva ${ }^{1}$, Daniela Fernandes Ramos ${ }^{1}$

${ }^{1}$ Universidade Federal do Rio Grande, Rio Grande, RS, Brasil. ${ }^{2}$ Instituto Nacional de Pesquisas da Amazônia (INPA), Manaus, AM, Brasil.

Submissão: 01/09/2016

Aceite: 16/09/2016

daniferamos@gmail.com

\begin{abstract}
RESUMO
Justificativa e objetivos: A vasta biodiversidade amazônica tem sido apontada como uma fonte de produtos naturais candidatos a diversas atividades farmacológicas, principalmente no combate a doenças infecciosas. Algumas espécies, tais como as pertencentes ao gênero Duroia, da família Rubiaceae, têm sido caracterizadas pela produção de metabólitos secundários com propriedades biológicas importantes, porém são escassos os estudos com espécies deste gênero. Desta forma, o objetivo deste estudo foi avaliar a atividade antimicobacteriana, antifúngica e antiparasitária de extratos de $D$. macrophylla e D. saccifera. Métodos: Foram coletados materiais vegetais de $D$. macrophylla e D. saccifera na Reserva Florestal A. Ducke em Manaus- AM, a partir dos quais foram preparados extratos diclorometânico, metanólico e aquoso e determinada a concentração inibitória e concentração larvicida mínima. Resultados: No que diz respeito aos extratos de D. saccifera, o extrato diclorometânico dos galhos foi o mais ativo frente às espécies fúngicas e as cepas micobacterianas avaliadas. Por outro lado, o extrato metanólico e o diclorometânico das folhas de D. macrophylla, foram os mais ativos frente a Candida sp. e Mycobacterium tuberculosis, respectivamente, porém, nenhum dos seis extratos avaliados apresentaram atividade antiparasitária frente a Toxocara canis. Conclusão: Esses resultados demonstram as propriedades antimicrobianas dessas plantas amazônicas para o desenvolvimento de novas alternativas terapêuticas no tratamento de doenças infecciosas, tais como a tuberculose e candidíase.
\end{abstract}

DESCRITORES: Candida. Rubiaceae. Mycobacterium tuberculosis. Toxocara canis.

\section{ABSTRACT}

Bachground and objective: The wide Amazonian biodiversity has been identified as a source of natural product candidates to various pharmacological activities, particularly in combating infectious diseases. Some species, such as the genus Duroia, belonging to the Rubiaceae family, has been characterized by the production of secondary metabolites with important biological properties, but there are few studies with species of this genus. Thus, the objective of this study was to evaluate the antimycobacterial, 
antifungal and antiparasitic activity of D. macrophylla and D. saccifera extracts by determining the minimum inhibitory concentration and minimum larvicide concentration. Methods: Were collected plant materials of the D. macrophylla and D. saccifera in Forest Reserve A. Ducke in Manaus AM, from which were prepared dichloromethane, methanol and aqueous extracts and determined the minimum inhibitory concentration and larvicidal concentration. Results: With regard to $D$. saccifera, extracts the dichloromethane extract of the branches was the most active against the fungal species and mycobacterial strains evaluated. On the other hand, the methanol and dichloromethane extract of the D. macrophylla leaves, were most active against Candida sp. and Mycobacterium tuberculosis, respectively, but none of the six evaluated extracts showed antiparasitic activity against Toxocara canis. Conclusion: These results demonstrate the antimicrobial properties of these Amazonian plants for the development of new therapies in the treatment of infectious diseases such as tuberculosis and candidiasis.

KEYWORDS: Candida. Rubiaceae. Mycobacterium tuberculosis. Toxocara canis.

\section{INTRODUÇÃO}

O Brasil é um dos países com a maior diversidade genética de plantas em todo o mundo. Nesta região são mais de 55.000 espécies catalogadas de um total estimado entre 350.000 e 550.000 . No entanto, estima-se que apenas $8 \%$ das espécies de plantas da flora brasileira foram estudadas quanto a sua bioatividade e apenas 1.100 espécies foram avaliadas quanto as suas propriedades medicinais. ${ }^{1}$ A vasta biodiversidade da Amazônia tem representado uma fonte potencial para a descoberta de novos agentes terapêuticos. ${ }^{1-4}$ Das 80.000 espécies de plantas superiores da Amazônia, menos de 2\% já foram investigadas quanto as suas atividades farmacológicas. ${ }^{5}$

Rubiaceae é a maior família da classe Magnoliopsida, abrangendo cerca de 611 gêneros e 13143 espécies. ${ }^{6-8}$ A família é caracterizada pela produção de várias classes de metabólitos secundários, com um grande potencial farmacológico, principalmente alcaloides, terpenos, ácido quinóvico glicosídeo, flavonoides, e cumarinas com propriedades antimicrobianas, principalmente frente a microrganismos patogênicos. $6,7,9,10$

O gênero Duroia, pertencente à tribo Gardenieae e subfamília Ixoroideae, detém cerca de 30 espécies, e poucos estudos têm sido realizados sobre este gênero. Este gênero apresenta espécies neotropicais na Costa Rica e América do Sul, caracterizando-se essencialmente pelas flores pistiladas e os frutos solitários. ${ }^{11-13}$

Espécies do gênero, tais como Duroia hirsuta, que é uma árvore notável na Amazônia Ocidental, têm sido identificadas com potencialidades alelopáticas e como possuidoras de atividades biológicas já identificadas em função da presença de 
diferentes metabólitos secundários. ${ }^{10,14-16}$ Mesmo assim, para as outras espécies do gênero, pouquíssimos estudos químicos e biológicos foram desenvolvidos. ${ }^{10,15}$

Duroia macrophylla Huber é uma árvore tropical que ocorre nas Guianas e no Brasil, onde tem vasta distribuição geográfica, com incidência nos estados do Pará, Amapá, Rondônia e Amazonas. Na reserva Ducke ocorre nas florestas de baixio, vertente e platô florescendo nos meses de novembro e dezembro e frutificando no período compreendido entre janeiro e junho..$^{13,17-19}$

D. macrophylla Huber, popularmente conhecida como "cabeça-de-urubú", "apuruí", ou" puruí-grande-da-mata", são árvores de tronco circular, digitada, com ramos quadrangulares, espessos, fistulosos e ferrugíneo-hirsutos, medindo $15-20 \mathrm{~m}$ de altura. As folhas são ternadas, longamente pecioladas, com lâmina ovada e lanceolada, coriácea com ápice acuminado, base obtusa, face adaxial glabra e abaxial pubérula. Observa-se a presença de estípulas ferrugíneo-tomentosas. As flores com corola creme se reúnem em inflorescências estaminadas, pediceladas, umbeladas e multifloras. Apresentam bagas solitárias, sésseis orbiculares, compridas e pubescentes. ${ }^{10,13,17}$

Duroia saccifera (Roem. \& Schult.) K. Schum ocorre na Venezuela, Colômbia, Peru e Brasil, nos estados do Amazonas, Pará, Roraima e Acre. É facilmente reconhecível mesmo em estado vegetativo pelo par de domácias conspícuas na base das folhas, habitadas por formigas muito pequenas, vermelhas e agressivas (Azteca sp.), além das folhas sésseis, ternadas e hirsutas. Na Reserva Ducke ocorre em florestas de platô, campinarana e até mesmo em capoeiras..$^{13,17}$

As árvores de $D$. saccifera medem 8 a $10 \mathrm{~m}$ de altura com tronco circular, base reta ou acanalada. Seus ramos são quadrangulares ou cilíndricos, escamosos com estípulas externamente hirsutas. As folhas ternadas, sésseis possuem a lâmina lanceolada, oblanceolada a obovada, hirsuta com ápice agudo, base aguda com um par de domácias sacciformes e nervuras laterais. Possui inflorescências estaminadas cimosas ou umbeladas. Podem apresentar flores estaminadas com pedicelos externamente hirsutos e corola creme, esparsamente pilosa e flores pistiladas solitárias são sésseis com cálice pubescente, denteado e corola lobada. Bagas subglobosas ou elipsóides, ligeiramente costadas, hirsutas..$^{13,17}$

Muitas espécies de Duroia sp., aparentemente, nunca foram quimicamente estudadas, mesmo assim, na medicina popular, o sumo da madeira produzida por uma espécie de Duroia é misturado com um yoco (Paullinia Yoco) e tem sido utilizado por índios Colombianos para dar força para uma doença que causa fraqueza excessiva 
chamado "papa-din". ${ }^{20}$ Devido à falta de relatos da atividade biológica de $D$. macrophylla e D. saccifera, o presente estudo teve por objetivo avaliar a atividade antimicrobiana, antifúngica e antiparasitária dos extratos diclorometânico, metanólico e aquoso das folhas e galhos destas espécies, através da determinação da concentração inibitória mínima (CIM) e concentração larvicida mínima (CLM).

\section{MÉTODOS}

\section{Material botânico e Preparação dos extratos}

Os materiais vegetais foram coletados na Reserva Florestal A. Ducke, uma área de $100 \mathrm{~km}^{2}$, localizada a $26 \mathrm{~km}$ NE de Manaus, na rodovia AM-010, AM. O material botânico das espécies de Duroia foi identificado e depositado no Herbário do Instituto Nacional de Pesquisas da Amazônia - INPA.

O material vegetal (folhas e galhos) foi seco em estufa a $50{ }^{\circ} \mathrm{C}$ e posteriormente triturado em moinho de facas. Folhas e galhos foram submetidos à extração com solventes de polaridade crescente (diclorometano, metanol e água). Foram realizadas três extrações utilizando banho de ultrassom por 20 minutos. Após filtração, os extratos diclorometânico e metanólico foram concentrados em rota-evaporador (Figura 1).

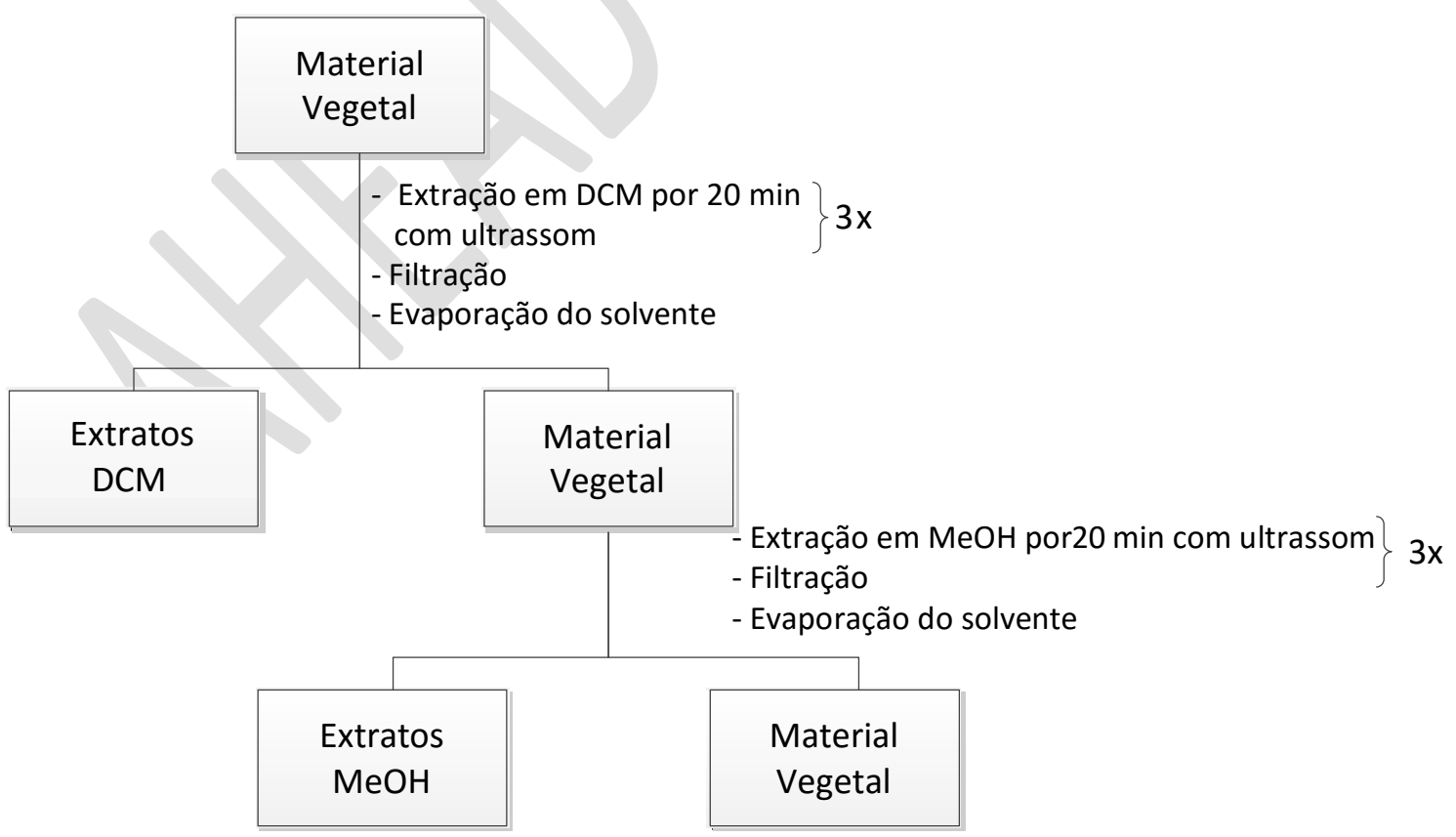

Figura 1 - Fluxograma da preparação dos extratos de galhos e folhas de ambas as espécies de Duroia.

\section{Avaliação da atividade antimicrobiana}


A atividade antimicrobiana foi verificada in vitro, pela determinação da concentração inibitória mínima (CIM). Os extratos foram testados frente aos seguintes microrganismos: Candida albicans (ATCC 11006), Candida glabrata (ATCC 2001), Candida parapsilosis (ATCC 22019), M. tuberculosis H37Rv (ATCC 27294), M. tuberculosis monorresistente a isoniazida (INHr - ATCC 35822) com mutação em katG S315T (AGC-ACC) e M. tuberculosis monorresistente a rifampicina (RIFr -ATCC 35338), com mutação em rpoB H526Y (CAC-TAC).

Os microrganismos foram cultivados em meio de cultura específico, e posteriormente, a atividade antifúngica (concentrações de 2 a $0,625 \mathrm{mg} / \mathrm{mL}$ ) dos extratos, foi determinada usando microdiluição 1:2 em caldo conforme padronizado pelo NCCLS-CLSI. ${ }^{21}$ Enquanto, a atividade antimicobacteriana foi determinada através do método de REMA (Resazurin Microtitre Assay), conforme descrito previamente por Palomino e colaboradores, sendo que as concentrações variaram de 0,4 a $0,006 \mathrm{mg} / \mathrm{mL}$. 22

\section{Avaliação da atividade anti-parasitária}

Cães de cinco a oito semanas foram tratados com pamoato de pirantel (15 $\mathrm{mg} / \mathrm{Kg}$ ) por via oral para obtenção de fêmeas adultas de $T$. canis, as quais foram submetidas à histerectomia para colheita de ovos não embrionados. ${ }^{23}$ Estes foram mantidos em solução de formalina a $2 \%$, a $28^{\circ} \mathrm{C}$, com umidade superior a $90 \%$ e oxigenação diária por 30 dias. ${ }^{24}$ Após o embrionamento, foi realizada a eclosão in vitro e a colheita de larvas infectantes (larvas de terceiro estádio), de acordo com a metodologia descrita por De Savigny (1975). ${ }^{25}$

O teste in vitro da ação larvicida dos extratos de Duroia sp. foi baseado na metodologia de Mata-Santos e colaboradores, sendo o extrato vegetal testado na concentração de $1 \mathrm{mg} / \mathrm{mL}$ (duplicata) em $200 \mu \mathrm{L}$ de meio de cultivo RPMI-1640 contendo 100 larvas de $T$. canis. ${ }^{26} \mathrm{O}$ material foi incubado a $37{ }^{\circ} \mathrm{C}$, em tensão de $\mathrm{CO}_{2}$ de 5\% e após 48 horas foi realizada por microscopia óptica a avaliação da viabilidade das larvas através do indicador de viabilidade celular azul de Tripan 0,4\%, da motilidade e da morfologia da cutícula e dos órgãos internos das larvas de T. canis, agente etiológico da parasitose tecidual denominada de síndrome da larva migrans visceral.

\section{RESULTADOS}


Neste estudo, verificou-se, pelo método microdiluição, a atividade antimicrobiana dos extratos aquosos, metanólicos e diclorometânicos das folhas e galhos de Duroia macrophylla e D. saccifera. Entre os seis extratos vegetais de $D$. saccifera testados, o extrato diclorometânico dos galhos foi o que apresentou melhor atividade antimicrobiana frente às espécies fúngicas e micobacterianas avaliadas (Tabela 1).

Tabela 1 - Atividade antimicrobiana (em mg/mL) dos extratos de Duroia macrophylla e D. saccifera.

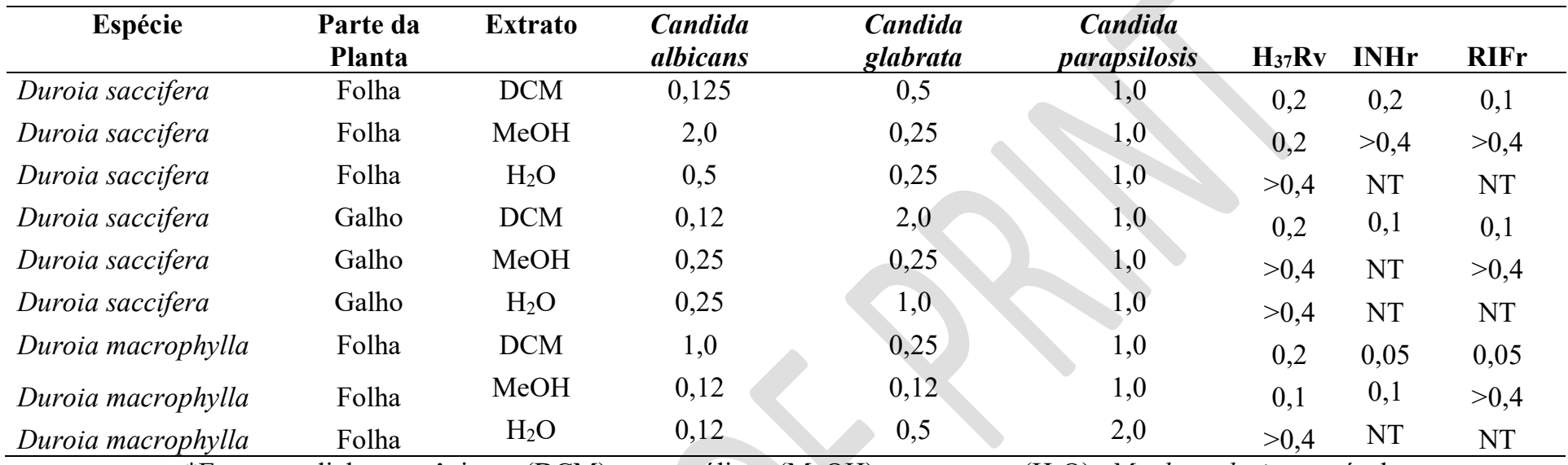

*Extratos diclorometânicos (DCM), metanólico (MeOH) e aquoso $\left(\mathrm{H}_{2} \mathrm{O}\right)$ M.tuberculosis sensível $\left(\mathrm{H}_{37} \mathrm{Rv}\right)$; monorresistente a isoniazida (INHr) e monorresistente a rifampicina (RIFr); Não testado (NT).

Em relação à atividade antifúngica, todos os extratos de ambas as espécies de Duroia testadas, mostraram atividade com CMI entre 2 e $0,125 \mathrm{mg} / \mathrm{mL}$. Os extratos diclorometânicos dos galhos e folhas de $D$. saccifera e metanólico e aquoso das folhas de D. macrophylla, apresentaram as menores CMI frente a C. albicans $(0,125 \mathrm{mg} / \mathrm{mL})$, seguidos dos extratos metanólico e aquoso dos galhos $(0,25 \mathrm{mg} / \mathrm{ml})$ de Duroia saccifera e aquoso das folhas da mesma planta $(0,5 \mathrm{mg} / \mathrm{mL})$. Os extratos diclorometânico das folhas de $D$. macrophylla e metanólico das folhas de D. saccifera apresentaram atividade moderada em relação aos demais extratos testados frente a C. albicans.

Apenas o extrato metanólico das folhas de D. macrophylla apresentou CMI de $0,125 \mathrm{mg} / \mathrm{mL}$ frente a C. glabrata, conforme ilustrado na Tabela 1. Além disso, as maiores atividades antimicrobianas frente a esta espécie fúngica foram identificadas nos três extratos das folhas de D. macrophylla - com CMI de $0,125 \mathrm{mg} / \mathrm{mL}$ (extrato metanólico), 0,25mg/mL (extrato diclorometânico) e $0,5 \mathrm{mg} / \mathrm{mL}$ (extrato aquoso) - e de D. saccifera com CMI de $0,25 \mathrm{mg} / \mathrm{mL}$ (extratos metanólico e aquoso) a $0,5 \mathrm{mg} / \mathrm{mL}$ (extato diclorometânico). Portanto, pode-se inferir que a atividade antimicrobiana frente a C. glabrata, está associada a constituintes das folhas das duas espécies de Duroia sp. 
testadas, principalmente aos extratos metanólicos, já que, mesmo os galhos de $D$. saccifera também apresentaram forte atividade, com CMI de $0,25 \mathrm{mg} / \mathrm{mL}$, nos extratos metanólicos.

Esses resultados mostraram que $C$. albicans foi mais sensível à atividade antifúngica dos extratos testados, seguida de C. glabrata e C. parapsilosis. Para essa última, todos os extratos testados tiveram atividade, porém com CMI de $1 \mathrm{mg} / \mathrm{mL}$, e, excepcionalmente, $2 \mathrm{mg} / \mathrm{mL}$ para o extrato aquoso das folhas de D. macrophylla.

Quando avaliada a atividade frente às três cepas de Mycobacterium tuberculosis, pode-se observar que o extrato aquoso das folhas e galhos de ambas as espécies vegetais avaliadas não mostraram atividade, a $0,4 \mathrm{mg} / \mathrm{mL}$. Neste trabalho foi possível observar, ainda, que D. macrophylla apresentou maior atividade antimicobacteriana frente as três cepas analisadas no que diz relação a CMI, que variou de 0,05 a $0,2 \mathrm{mg} / \mathrm{mL}$. Sendo que, o extratos diclorometânico e metanólico das folhas apresentaram CMI de 0,2 e 0,05 mg/mL frente as três cepas estudadas e o extrato metanólico das folhas não teve atividade frente a cepa resistente a rifampicina.

D. saccifera apresentou atividade frente às cepas de M. tuberculosis avaliadas, apenas nos extratos diclorometânico das folhas e galho com CMI de 0,2 e $0,1 \mathrm{mg} / \mathrm{mL}$ e no extrato metanólico das folhas com CMI de $0,4 \mathrm{mg} / \mathrm{mL}$, apenas frente a $M$. tuberculosis sensível. As menores CMIs encontradas $(0,05 \mathrm{mg} / \mathrm{mL})$ foram do extrato das folhas de D. macrophylla, seguidos dos galhos de D. saccifera $(0,1 \mathrm{mg} / \mathrm{mL}) \mathrm{em}$ diclorometano, frente as cepas resistentes a isoniazida e rifampicina e do extrato metanólico de D. macrophylla frente a cepas de M. tuberculosis H37Rv e INHr. Estes resultados evidenciam que a atividade antimicobacteriana pode estar relacionada com constituintes presentes, principalmente, nos extratos diclorometânico das folhas e galhos das duas espécies da família Rubiaceae analisadas.

\section{DISCUSSÃO}

Rubiaceae é uma família de plantas com flores que possuem uma grande coleção de plantas medicinais, cujas atividades já foram identificadas para 48 gêneros desta família frente a diversos patógenos. ${ }^{7}$ Dos três extratos de D. macrophylla testados, o extrato metanólico das folhas foi o mais ativo considerando o conjunto das espécies de Candida sp. e Mycobacterium sp. Extratos metanólicos, etanólicos e clorofórmicos de plantas desta família já foram identificados como mais ativos frente a agentes 
patogênicos, devido à presença de princípios bioativos potentes nestes extratos brutos que podem ser úteis como antimicrobianos. ${ }^{27}$

Estudo em Ohio, relatou que diferentes solventes devem ter a capacidade de extrair diferentes fitoconstituintes dependendo da solubilidade ou polaridade dos solventes. ${ }^{28}$ Portanto, a atividade antifúngica testada frente a $C$. albicans pode estar associada com constituintes presentes nos extratos diclorometânicos tanto da folha quanto dos galhos de D. saccifera, diferentemente, de D. macrophylla onde as maiores atividades estão relacionadas aos extratos metanólico e aquoso das folhas. Extratos diclorometânicos e metanólicos de outras espécies da família Rubiaceae já tiveram moderada atividade antifúngica demonstrada frente a C. albicans. ${ }^{29-32}$

Candida albicans tem sido responsável por 50-60\% das infecções nosocomiais, contudo, a ocorrência de espécies "não-albicans" (C. tropicalis, C. krusei, C. parapsilosis, C. glabrata) tem sido relatada. ${ }^{33}$ Apesar das espécies "não-albicans" serem menos invasivas e virulentas, têm mostrado menor susceptibilidades aos antifúngicos. ${ }^{34}$ Neste estudo, o padrão de sensibilidade das três espécies de Candida sp. testadas foi semelhante ao padrão descrito para os antifúngicos, sendo C. albicans $>C$. glabrata $>$ C. parapsilosis.

Com relação a atividade frente às cepas de $M$. tuberculosis sensível e resistente a isoniazida e rifampicina, para ambas as espécies da família Rubiaceae, os extratos em diclorometano foram os que apresentaram maior atividade antibacteriana. Esses resultados já foram identificados em outros estudos com extratos de D. macrophylla e D. hirsuta, inclusive frente a cepas resistentes. ${ }^{10,27,35,36}$ Além disso, outros autores tem proposto um amplo espectro de atividade antimicrobiana (antifúngica e antibacteriana) de extratos de partes aéreas de plantas da família Rubiaceae., ${ }^{6,37}$

Os extratos de $D$. saccifera apresentaram valores de CMI semelhantes tanto nas atividades antimicobacterianas quanto antifúngicas, porém, apenas os extratos diclorometânico e metanólico das folhas e diclorometânico dos galhos apresentaram atividade frente às cepas de $M$. tuberculosis testadas. Outros estudos de atividade antimicrobiana de plantas da família Rubiaceae identificaram atividade desses solventes em extratos vegetais frente a $C$. albicans e inatividade frente às diferentes espécies bacterianas, tais como, P. aeruginosa e E. coli. ${ }^{6,37,38}$

Vários metabólitos secundários isolados de plantas, como alcalóides, flavonóides, taninos, terpenóides, entre outros têm demonstrado várias atividades biológicas. Estes componentes fitoquímicos têm sido descritos por promover diversos 
efeitos farmacológicos, como a atividade antiinflamatória, imunomoduladora, antioxidante, diurética, antiespasmódica, antimicrobiana e anticancerígena. ${ }^{6,37,38} \mathrm{~A}$ presença de alcalóides e terpenóides, comumente relatada em plantas da família Rubiaceae poderia explicar a atividade e o amplo espectro de ação dos extratos de $D$. macrophylla e D. saccifera encontrados neste estudo. ${ }^{1,19,36}$

Os resultados da presente pesquisa permitem identificar um amplo espectro de ação destes extratos tanto para as espécies de Candida sp. quanto para as espécies micobacteriana avaliadas. Possivelmente devido a forte influência dos fitoconstituintes presentes nos diferentes extratos testados, que podem estar associados a diferentes atividades antibacterianas e antifúngicas. Prospecções fitoquímicas de extratos diclorometânicos das folhas de outras plantas desta família, já tiveram sua atividade antimicobacteriana comprovada e atribuída à presença de terpenos e alcaloides. ${ }^{10,39,40}$

Análises desses constituintes responsáveis pela bioatividade têm sido propostas, tais como, no caso dos terpenóides, com atividade antimicobacteriana já identificada anteriormente, que mesmo sem ter seu mecanismo de ação totalmente elucidado, tem estimulado especulações sobre seu envolvimento no rompimento da membrana celular através dos seus compostos lipofílicos. ${ }^{40-43}$ Já os compostos nitrogenados heterocíclicos conhecidos como alcaloides, tem tido suas atividades biológicas relacionadas com sua variedade estrutural, portanto, diversos extratos vegetais contendo esses fitoconstituintes, foram identificados como inibidores da RNA polimerase, girase e topoisomerase IV e dos ácidos nucleicos, frente a bactérias, fungos, protozoários e vírus. ${ }^{44,45}$

Atualmente diversos estudos têm sido realizados identificando a importância de substâncias naturais no tratamento de doenças humanas. Entre as 109 novas drogas antibacterianas, aprovadas no período de 1981 a 2014, 73\% tiveram origem em produtos naturais. Em contraste, apenas $10 \%$ das drogas antifúngicas são de origem natural ou de produtos que mimetizam produtos naturais. ${ }^{46}$

Metabólitos secundários de plantas têm sido identificados como compostos de grande importância terapêutica. A diversidade de espécie vegetal, a topografia e clima do país de origem, pode influenciar na composição de diferentes categorias de princípios ativos, que conferem diferentes atividade antimicrobianas. Em nosso trabalho, foi possível identificar a atividade antimicrobiana dos extratos vegetais de duas espécies da família Rubiaceae presentes na Amazônia brasileira. 
Os extratos das folhas de D. macrophylla foram os mais ativos tanto frente às espécies fúngicas quanto micobacterianas testadas, sendo que o extrato metanólico foi o mais ativo frente as três espécies de Candida sp. e o extrato diclorometânico frente as três cepas de $M$. tuberculosis, demonstrando a potencialidade dos extratos de $D$. macrophylla para o desenvolvimento de novos antimicrobianos.

Nesta pesquisa ficaram demonstradas as atividades antibacterianas e antifúngicas dos extratos de D. saccifera e D. macropyla (Rubiaceae), sendo que o extrato diclorometânico de D. macrophylla foi mais ativo frente às cepas de $M$. tuberculosis resistente a isoniazida e rifampicina, bem como, os extratos diclorometânicos das folhas e galhos de D. saccifera, enquanto, o extrato metanólico de D. macrophylla foi o mais ativo frente às três espécies fúngicas testadas. Porém, com relação à atividade antiparasitária, em nosso estudo, nenhum extrato vegetal testado foi ativo a $1 \mathrm{mg} / \mathrm{mL}$ frente ao Toxocara cannis.

Mesmo assim, algumas questões devem ser levadas em consideração com relação às atividades antimicrobianas de extratos naturais brutos, já que, uma atividade forte (CMI baixos), podem estar associadas à interação das atividades de diversos componentes e portanto, poderia modificar-se ao longo do isolamento pela busca de uma única substância ativa, reduzindo sua atividade quando comparada com o extrato bruto. ${ }^{47}$ Sendo assim, esses resultados estimulam o estudo dos princípios ativos e os mecanismos de ação envolvidos nas atividades antimicrobianas identificadas, a fim de desenvolver novas drogas antimicrobianas que venham a contribuir para a terapêutica de doenças infecciosas de grande impacto clínico, como é o caso da tuberculose e candidíase, a partir de extratos vegetais da família Rubiaceae oriundos da Amazônia.

AGRADECIMENTOS: $\mathrm{CNPq}-\mathrm{MCTI} / \mathrm{CNPq} \mathrm{n}^{\circ} 14 / 2013$

\section{REFERÊNCIAS:}

1. Simões CMO, Schenkel EP, Gosmann G, et al. Farmacognosia: da planta ao medicamento. $5^{\circ}$ ed. Porto Alegre/Florianópolis: UFSC; 2003.

2. Brandao MG, Zanetti NN, Oliveira $P$, et al. Brazilian medicinal plants described by 19th century European naturalists and in the Official Pharmacopoeia. J Ethnopharmacol 2008 20; 120(2):141-8. DOI: http://dx.doi.org/ 10.1016/j.jep.2008.08.004. 
3. Svetaz L, Zuljan F, Derita M, et al. Value of the ethnomedical information for the discovery of plants with antifungal properties. A survey among seven Latin American countries. J Ethnopharmacol 2010 8; 127(1):137-58. DOI: http://dx.doi.org/ 10.1016/j.jep.2009.09.034.

4. Duarte MC, Figueira GM, Sartoratto A, et al. Anti-Candida activity of Brazilian medicinal plants. J Ethnopharmacol 2005 28;97(2):305-11. DOI: http://dx.doi.org/10.1016/j.jep.2004.11.016.

5. Elisabetsky E, Shanley P. Ethnopharmacology in the Brazilian Amazon. Pharmacol Ther 1994; 64(2):201-14.

6. Kala SC. Medicinal Attributes of family Rubiaceae. International J Pharmacy Biological Sci 2015; 5(2):179-81.

7. Choudhury KD, Choudhury MD, Baruah M. Antibacterial activity of some plants belonging to the family rubiaceae: A review. World J Pharmacy Pharmaceutical Sci 2012; 1 (3):1179-1194.

8. Govaerts R, Ruhsam M, Andersson L, et al. World Checklist of Rubiaceae. The Board of Trustees of the Royal Botanic Gardens, Kew. 2016.

9. Martins D, Nunez CV. Secondary Metabolites from Rubiaceae Species. Molecules 2015; 20(7):13422-95. DOI: http://dx.doi.org/ 10.3390/molecules200713422.

10. Martins D, Carrion LL, Ramos DF, et al. Triterpenes and the Antimycobacterial Activity of Duroia macrophylla Huber (Rubiaceae). BioMed Research International 2013; 2013:1-7. DOI: http://dx.doi.org/10.1155/2013/605831.

11. Chiquieri A, Di Maio FR, Peixoto AL. A distribuição geográfica da família Rubiaceae Juss. na Flora Brasiliensis de Martius. Rodriguésia 2004; 55(84): 47-57.

12. Bremer B. A review of molecular phylogenetic studies of Rubiaceae. Annals of the Missouri Botanical Garden 2009; 96(1): 4-26. DOI: http://dx.doi.org/10.3417/2006197. 
13. Taylor CM, Campos MTVA, Zappi D. Flora da Reserva Ducke, Amazonas, Brasil: Rubiaceae. Rodriguésia 2007; 58(3):549-616.

14. Lopez A, Hudson JB, Towers GH. Antiviral and antimicrobial activities of Colombian medicinal plants. J Ethnopharmacol 2001; 77(2-3): 189-96.

15. Aquino R, Tommasi ND, Tapia M, et al. New 3-methyoxyflavones, an iridoid lactone and a flavonol from Duroia hirsuta. J Nat Prod 1999; 62 (4):560-2. DOI: http://dx.doi.org/10.1021/np9803631.

16. Nunez CV, Roumy V, Mesquita DWO, et al. Indole alkaloids from Duroia macrophylla (Rubiaceae). Planta Medica 2012; 78. DOI: http://dx.doi.org/ 10.1055/s0032-1320974.

17. Campos MTVA, Brito JM. Rubiaceae. In: Ribeiro ELS, Hopkins MJG, Vincentini A, et al., editors. Flora da Reserva Ducke: Guia de identificação das plantas vasculares de uma floresta de terra-firme na Amazônia Central. INPA ed. 1999. p. 626-33.

18. Ribeiro JELS, Hopkins MJG, Vicentini A, et al. Flora da Reserva Ducke. Guia de identificação das plantas em uma floresta de terra firme na Amazônia central. Instituto Nacional de Pesquisas da Amazonia (INPA) and Department for International Development (DFID) ed. Manaus: 1999.

19. Nunez CV, Santos PA, Roumy V, et al. Raunitidine isolated from Duroia macrophylla (Rubiaceae). Planta Medica 2009; 75: 877-1095. DOI: http://dx.doi.org/ $10.1055 / \mathrm{s}-0029-1234835$.

20. Schultes RE. Plants in treating senile dementia in the northwest Amazon. J Ethnopharmacol 1993; 38 (2-3): 129-35. DOI: http://dx.doi.org/10.1016/03788741(93)90007-R.

21. NCCLS- CLSI. National Committee for Clinical Laboratory Standards (NCCLS): Performance Standards for Antimicrobial Disc Susceptibility Tests. Approved Standard M2-A7. 2003. 
22. Palomino JC, Martin A, Camacho M, et al. Resazurin microtiter assay plate: simple and inexpensive method for detection of drug resistance in Mycobacterium tuberculosis. Antimicrob Agents Chemother 2002; 46(8):2720-2. DOI: http://dx.doi.org/10.1128/AAC.46.8.2720-2722.2002.

23. Avila LFC, Conceição RCR, Telmo PL, et al. Saccharomyces boulardii reduces infection intensity of mice with toxocariasis. Veterinary Parasitology 2012 8; 187(12):337-40. DOI: http://dx.doi.org/10.1016/j.vetpar.2012.01.002.

24. Nunes CM. Imunodiagnóstico da larva migrans visceral através de um método de ELISA indireto competitivo [Doutorado Faculdade de Medicina Veterinária e Zootecnia da Universidade de São Paulo; 1996.

25. Savigny DH. In vitro maintenance of Toxocara canis larvae and a simple method for the production of Toxocara ES antigen for use in serodiagnostic tests for visceral larva migrans. J Parasitol 1975; 61(4): 781-2.

26. Mata-Santos T, Pinto NF, Mata-Santos HÁ, et al. Anthelmintic Activity of Lapachol, beta-Lapachone and its derivatives against Toxocara canis larvae. Rev Inst Med Trop 2015; 57(3):197-214. DOI: http://dx.doi.org/10.1590/S003646652015000300003.

27. Carrion LL, Ramos DF, Martins D, et al. Antymicobacterial activity of Brazilian Amazon plants extracts. International Journal of Phytomedicine 2013; 5 (4):479-85. DOI: http://dx.doi.org/10.5138/ijpm.v5i4.1202.

28. Cowan MM. Plant products as antimicrobial agents. Clin Microbiol Rev 1999; 12(4):564-82. DOI: http://dx.doi.org/0893-8512/99/\$04.0010.

29. Nino J, Mosquera OM, Correa YM. Antibacterial and antifungal activities of crude plant extracts from Colombian biodiversity. Rev Biol Trop 2012; 60(4):1535-42. DOI: http://dx.doi.org/ 10.15517/rbt.v60i4.2071. 
30. Figueiredo $\mathrm{AD}$, Bustamente $\mathrm{KG}$, Soares $\mathrm{ML}$, et al. Avaliação da atividade antimicrobiana das partes aéreas (folhas e caules) e raízes de Richardia brasiliensis Gomez (Rubiaceae). Rev Ciênc Farm Básica Apl 2009; 30(2): 193-6.

31. Tangarife-Castaño V, Correa-Royero J, Zapata-Londoño B, et al. Anti-Candida albicans activity, cytotoxicity and interaction with antifungal drugs of essential oils and extracts from aromatic and medicinal plants. Infectio 2011; 15(3): 160-7. DOI: http://dx.doi.org/10.1016/S0123-9392(11)70080-7.

32. Rodrigues K, Ramos DF, Carrion LL, et al. Antifungal activity of Brazilian Amazon plants extracts against some species of Candida spp. Intern J Phytopharmacology 2014; 5(6): 445-53.

33. Klafke GB, Moreira GM, Monte LG, et al. Assessment of plant lectin antifungal potential against yeasts of major importance in medical mycology. Mycopathologia 2013; 175(1-2):147-51. DOI: http://dx.doi.org/ 10.1007/s11046-012-9596-x.

34. Shahin J, Allen EJ, Patel K, Muskett H, et al. Predicting invasive fungal disease due to Candida species in non-neutropenic, critically ill, adult patitents in United Kingdom critical care units. BMC Infectious Diseases 2016; 16: 480: 1-10. DOI: http://dx.doi.org/10.1186/s12879-016-1803-9.

35. Usha R, Sashidharan S, Palaniswamy M. Antimicrobial Activity of a Rarely Known Species, Morinda citrifolia L. Ethnobotanical Leaflets 2010; 14:306-11.

36. Ramos DF, Leitão GG, Costa FN, et al. Investigation of the antimycobacterial activity of 36 plant extracts from the brazilian Atlantic Forest. Brazilian J Pharmaceutical Sci 2008; 44(4): 669-674. DOI: http://dx.doi.org/10.1590/S151693322008000400013.

37. Conserva KM, Ferreira JC. Borreria and Spermacoce species (Rubiaceae): A review of their ethnomedicinal properties, chemical constituents, and biological activities. Pharmacognosy Reviews 2012; 6(11):46-55. DOI: http://dx.doi.org/doi:10.4103/0973-7847.95866. 
38. Wong KY, Vikram P, Chiruvella KK, et al. Phytochemical screening and antimicrobial potentials of Borreria sps (Rubiaceae). J King Saud University - Sci 2015; 27(4):302-11. DOI: http://dx.doi.org/10.1016/j.jksus.2014.12.001.

39. Savoia D. Plant-derived antimicrobial compounds: alternatives to antibiotics. Future Microbiol 2012; 7(8)979-90. DOI:http://dx.doi.org/10.2217/fmb.12.68.

40. Garcia A, Bocanegra-Garcia V, Palma-Nicolas JP, et al. Recent advances in antitubercular natural products. Eur J Med Chem 2012; 49: 1-23. DOI: http://dx.doi.org/ 10.1016/j.ejmech.2011.12.029.

41. Cushnie TP, Lamb AJ. Recent advances in understanding the antibacterial properties of flavonoids. Int $\mathrm{J}$ Antimicrob Agents 2011; 38(2):99-107. DOI: http://dx.doi.org/ 10.1016/j.ijantimicag.2011.02.014.

42. Kurek A, Grudniak AM, Kraczkiewicz-Dowjat A, et al. New antibacterial therapeutics and strategies. Pol J Microbiol 2011;60(1):3-12.

43. Termentzi A, Fokialakis N, Skaltsounis AL. Natural resins and bioactive natural products thereof as potential antimicrobial agents. Curr Pharm Des 2011; 17(13):126790.

44. Yi ZB, Yan Y, Liang YZ, et al. Evaluation of the antimicrobial mode of berberine by LC/ESI-MS combined with principal component analysis. J Pharm Biomed Anal 2007 9; 44(1):301-4. DOI: http://dx.doi.org/ 10.1016/j.jpba.2007.02.018.

45. Kim SH, Lee SJ, Lee JH, et al. Antimicrobial activity of 9-O-acyl- and 9-Oalkylberberrubine derivatives. Planta Med 2002; 68(3):277-81. DOI: http://dx.doi.org/10.1055/s-2002-23128.

46. Newman DJ, Cragg GM. Natural Products as Sources of New Drugs from 1981 to 2014. J Nat Prod 2016 25; 79(3):629-61. DOI: http://dx.doi.org/ 10.1021/acs.jnatprod.5b01055. 
47. Pauli GF, Case RJ, Inui $T$, et al. New perspectives on natural products in TB drug $\begin{array}{lllll}\text { research. } & \text { Life } & \text { Sci } & 2005 & \text { 78(5):485-94. }\end{array}$ http://dx.doi.org/10.1016/j.1fs.2005.09.004. 